\title{
SINGLE VENDOR-BUYER INTEGRATED INVENTORY SYSTEM FOR IMPERFECT PRODUCTION WITH VARIABLE LEAD TIME
}

\author{
R.Uthayakumar and M.Ganesh Kumar \\ Department of Mathematics, The Gandhigram Rural Institute - Deemed University, \\ Gandhigram - 624 302. Dindigul, Tamil Nadu, India.
}

\begin{abstract}
In this paper, the authors considered the single vendor single buyer integrated production inventory problem with stochastic demand for an imperfect production process. They relax the assumption that, the lead time is varying linearly with the lot size. That is, the lead time is composed of a lot size dependent run time and constant delay times such as moving, waiting and setup times. A solution procedure is mentioned for solving the proposed model and numerical examples are used to illustrate the benefit of integration. A sensitivity analysis is also performed to explore the effect of key parameter D (demand). A simple procedure is suggested to obtain an approximate solution of the proposed model. Examples are used to illustrate the model and explore the effect of important parameters on the production schedule and total expected cost.
\end{abstract}

\section{KEY WORDS}

Inventory production, Variable lead time, Economic order quantity, vendor-buyer, defective items and Inspection.

*Corresponding author Tel. +91-451-2452371, Fax: 91-451-2453071

\section{INTRODUCTION}

The single-vendor single-buyer cooperative production inventory model received a lot of interest in recent years by several researchers. The reason is this joint productive model has the skill to offer customers shorter waiting time and minimize the inventory cost. And also single-vendor single-buyer cooperative production helps to resolve the problem areas along the process enabling in trade to take vital action and further reduce price to get better the final value. The model is facing the customer is how much to order in each purchase order. On the other hand, the model is facing the seller is to make a decision the fiscal production batch size and the most economical number of shipments in which the whole order quantity to consumer will be supplied. Therefore, an integrated inventory rule is useful to decide the economic order quantity and shipment policy. 
Operations Research and Applications : An International Journal (ORAJ), Vol.3, No.1, February 2016

\section{LITERATURE REVIEW}

Banerjee [1] developed a joint economic-lot-size model for a special case where a seller produces to order for a consumer on a lot-for-lot basis. By modifying Banerjee's lot-for-lot assumption, Goyal [5] extend a more universal joint economic lot size problem that provided a lower-joint total relevant cost. Hoque and Goyal [7] developed an optimal solution procedure for the singlevendor single-buyer production-inventory structure with uneven and equal sized shipments from the seller to the consumer and under the capacity restriction of the transport tackle. This supposition is questioned by Kim and Benton [10] and considered the effect of lot size on lead time and safety stock. Kim and Benton [10] established a linear association between lead time and lot size based on explanation of Karmarkar [9]. They included this lead time lot size relation into the classical probabilistic continuous review $(Q, r)$ model.

In many literature, the single vendor-buyer integrated inventory model, that is frequently assumed that the shortages are not allowed and demand is deterministic. Ben-Daya and Hariga [2] extended this by taking the annual customer demand to be stochastic with variable lead time and thereby allowing shortages. Vandana, B.K.Sharma [13] allowing shortages and considered an economic ordered quantity model for retailers partial permissible delay in payment linked to order quantity. Most of studies deal with the perfect production process. Although production process is often considered to be ideal, but in reality, it is not possible that a manufacture progression is $100 \%$ defect-free. Huang [8] considered the imperfect production process. In that the defective percentage is considered among each lot size. In Vandana, B.K.Sharma., [14] an EPQ model with non-instantaneous deteriorating items are considered. In an integrated model, if the production is unsatisfactory then the seller who has to give warranty cost for faulty items, it is favorable to him, in particular, and to the supply chain as a whole, to spend amount (invest) in reducing the number of faulty items produced as in [12].

And finally Dey.O and Giri.B.C [4] developed the optimal vendor investment for reducing defect rate in vendor-buyer integrated system for imperfect production process. In that the production is imperfect in stochastic demand. This paper deals the similar case of Dey.O and Giri.B.C [4] but the lead time is linear in $Q$ and without any investment. Therefore we considered the stochastic demand, an imperfect production process and finite screening period in this paper.

\section{MODEL}

In this paper, we assume that the buyer is using a continuous review $(Q, r)$ inventory policy. The batch quantity and reorder level are often determined under the assumption of a constant lead time. However, from a real life point of view, lead time should be considered as a function of the production batch size. In this section, the classical $(Q, r)$ continuous review inventory policy with deterministic variable lead time is considered for the buyer. In particular, we assume that the lead time is proportional to the lot size produced by the vendor in addition to a fixed delay due to transportation, nonproductive time, etc., that is $L(Q)=p Q+b$.

To extend the proposed model, the following notations are used:

$D \quad$ Expected demand rate (units/unit time), 
Operations Research and Applications : An International Journal (ORAJ), Vol.3, No.1, February 2016

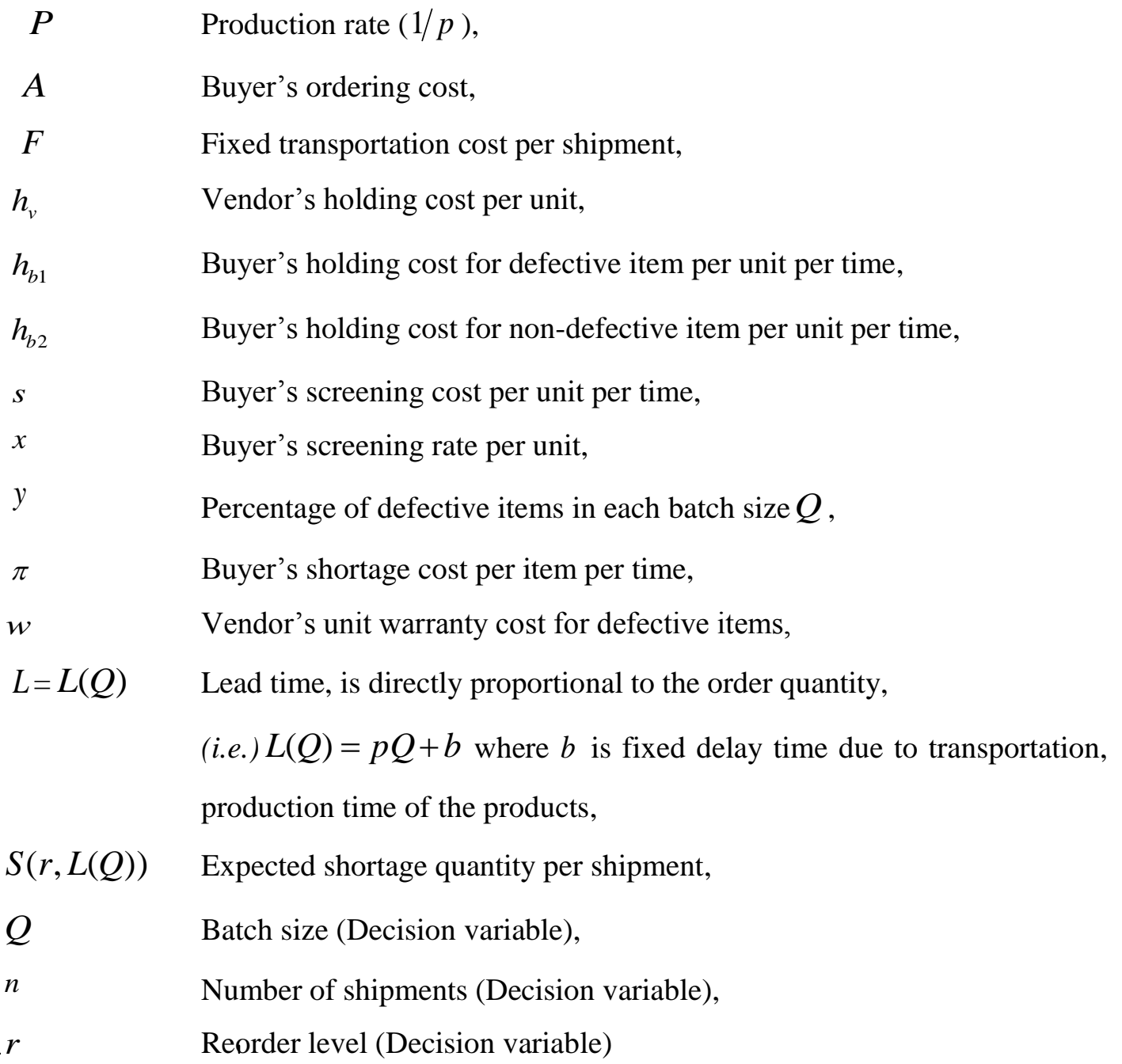

We develop the model with the following assumptions

- A single-vendor single-buyer integrated inventory model for a single item.

- Demand per unit time is normally distributed with mean $D$ and standard deviation $\sigma$.

- The buyer places an order for $n Q$ items. The vendor produces these items and gives to the buyer as $n$ equal shipments.

- The buyer follows the classical $(Q, r)$ continuous review with variable lead time $L(Q)=p Q+b$.

- The demand in lead time is normally distributed with mean $D L(Q)$ and standard deviation $\sigma \sqrt{L(Q)}$. 
Operations Research and Applications : An International Journal (ORAJ), Vol.3, No.1, February 2016

- The reorder level $r$ =Expected demand during lead time + safety stock $=D L(Q)+k \sigma \sqrt{L(Q)}$ where, $k \sigma \sqrt{L(Q)}$ is safety stock and $k$ is the safety factor.

- Shortages are allowed and completely backlogged.

- $\quad y$ is a percentage of defective items in each batch size $Q$.

- The non-defective production rate is greater than the demand rate.

(i.e.) $P(1-y)>D$.

- Unit screening rate is greater than the demand rate. (i.e.) $x>D$.

- The seller offers the warranty cost for the defective items to the consumer.

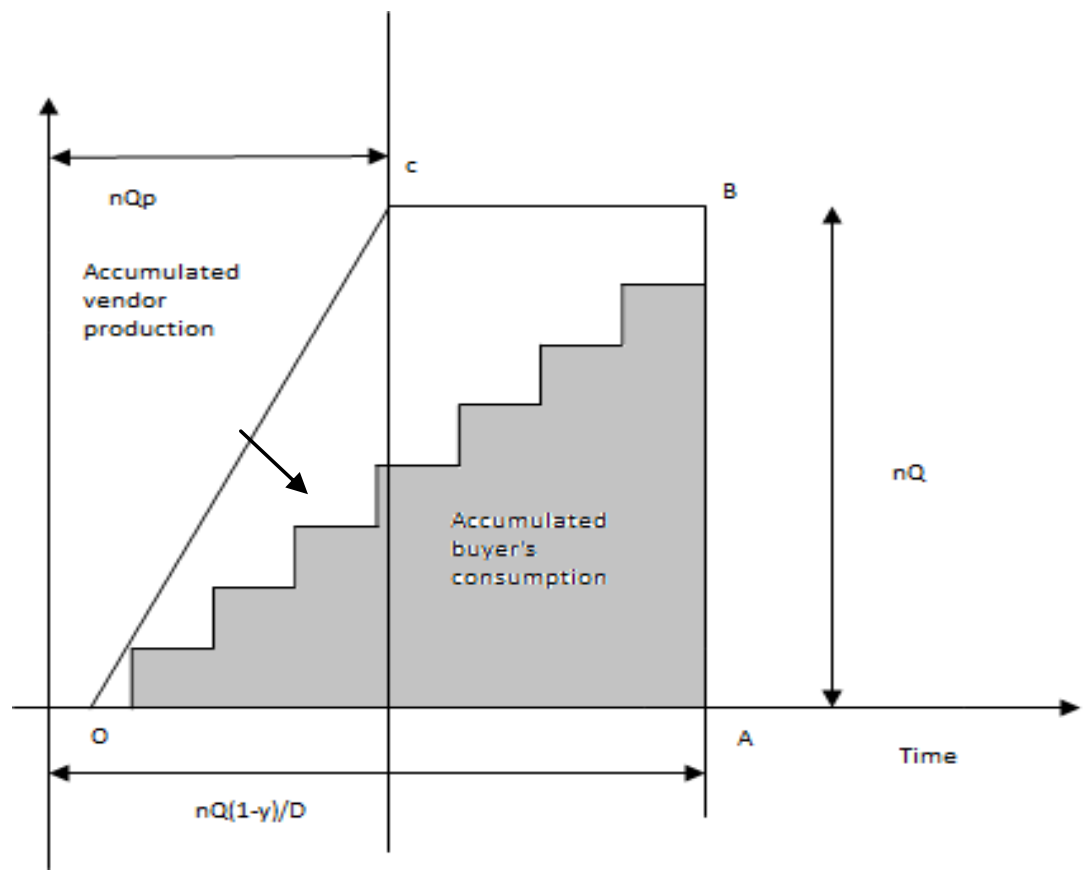

Fig : 1 Vendor buyer holding area.

The buyer places an order of size $Q$ for non defective items to the vendor. In order to reduce the production cost, the vendor produces $n Q$ items and transfers $Q$ batches of $n Q$ items each at regular intervals of $Q(1-y) / D$ units of time on average. The length of each ordering cycle is therefore $Q(1-y) / D$ and the length of the complete production cycle is $n Q(1-y) / D$. 
Operations Research and Applications : An International Journal (ORAJ), Vol.3, No.1, February 2016 Inventory profile for the vendor buyer is depicted in Fig 1

The problem is to find the number of shipments $n$, the shipment size $Q$, and the reorder point $r$, that minimize the total cost.

We assume the demand is normally distributed with mean $D$ and standard deviation $\sigma$. Therefore the demand during lead time also normally distributed with mean $D L(Q)$ and standard deviation $\sigma \sqrt{L(Q)}$.

Expected annual cost for the buyer is

$\operatorname{ETCB}(Q, k, n, L(Q))=\frac{D(A+n F)}{n Q(1-y)}+h_{b 1}\left(Q y-\frac{D Q y}{2 x(1-y)}\right)+h_{b 2}\left(k \sigma \sqrt{L(Q)}+\frac{Q(1-y)}{2}+\frac{D Q y}{2 x(1-y)}\right)$

$+\pi \frac{D}{Q(1-y)} S(r, L(Q))+s \frac{D}{1-y}$

where $S(r, L(Q))=\int_{r}^{\infty}(x-r) f(x, D L(Q), \sigma \sqrt{L(Q)}) d x, x$ is the demand during lead time with probability density function $f(x)$.

$$
\begin{aligned}
S(r, L(Q)) & =\int_{r}^{\infty}(x-r) f(x, D L(Q), \sigma \sqrt{L(Q)} d x \\
& =\sigma \sqrt{L(Q)} \int_{r}^{\infty}\left(\frac{x-D L(Q)}{\sigma \sqrt{L(Q)}}-\frac{r-D L(Q)}{\sigma \sqrt{L(Q)}}\right) \frac{1}{\sigma \sqrt{L(Q)} \sqrt{2 \pi}} e^{-\frac{1}{2}\left(\frac{x-D L(Q)}{\sigma \sqrt{L(Q)}}\right)^{2}} d x \\
& =\sigma \sqrt{L(Q)} \psi(k)
\end{aligned}
$$

where $\psi(k)=\int_{k}^{\infty}(z-k) \phi(z) d z, \quad \phi(z)$ is a standard normal probability density function, $z=\frac{x-D L(Q)}{\sigma \sqrt{L(Q)}}$, and $k=\frac{r-D L(Q)}{\sigma \sqrt{L(Q)}}$.

$\psi(k)$ may also written as

$$
\psi(k)=\int_{k}^{\infty}(z-k) \phi(z) d z
$$


Operations Research and Applications : An International Journal (ORAJ), Vol.3, No.1, February 2016

$$
\begin{aligned}
& =\frac{1}{\sqrt{2 \pi}} \int_{k}^{\infty} z e^{-\frac{z^{2}}{2}} d z-k\left(1-\int_{0}^{k} \phi(z) d z\right) \\
& =\frac{1}{\sqrt{2 \pi}} e^{-\frac{k^{2}}{2}}-k(1-F(k)) \\
& =\phi(k)-k \bar{F}(k)
\end{aligned}
$$

where $\bar{F}(k)$ is the complement of the cumulative distribution function. (i.e, ) $\bar{F}(k)=1-F(k)$

Now the expected annual cost for vendor is

$$
\operatorname{ETCV}(Q, n)=\frac{B D}{n Q(1-y)}+h_{v} \frac{Q}{2}\left[n\left(1-\frac{D p}{1-y}\right)-1+\frac{2 D p}{1-y}\right]+w \frac{D y}{1-y}
$$

Therefore the integrated annual expected cost is

$$
\begin{aligned}
& \operatorname{ETC}(Q, k, n, L(Q))=\frac{D(A+B+n F)}{n Q(1-y)}+h_{b 1}\left(Q y-\frac{D Q y}{2 x(1-y)}\right)+h_{b 2}\left(k \sigma \sqrt{L(Q)}+\frac{Q(1-y)}{2}+\frac{D Q y}{2 x(1-y)}\right) \\
& +\pi \frac{D \sigma \psi(k) \sqrt{L(Q)}}{Q(1-y)}+s \frac{D}{1-y}+\frac{B D}{n Q(1-y)}+h_{v} \frac{Q}{2}\left[n\left(1-\frac{D p}{1-y}\right)-1+\frac{2 D p}{1-y}\right]+w \frac{D y}{1-y}
\end{aligned}
$$

\section{Solution procedure}

The total cost function ETC is convex in $n$. Since it is easy to see that

$$
\begin{aligned}
& \frac{\partial}{\partial n} E T C=-\frac{D(A+B)}{n^{2} Q(1-y)}+h_{v} \frac{Q}{2}\left(1-\frac{D p}{1-y}\right) \\
& \frac{\partial^{2}}{\partial n^{2}} E T C=\frac{D(A+B)}{n^{3} Q(1-y)}>0 \quad \forall n \geq 1 .
\end{aligned}
$$

For fixed value of $n, E T C$ can also be shown to be convex in $k$.

$$
\begin{aligned}
\frac{\partial}{\partial k} E T C & =h_{b 2} \sigma \sqrt{L(Q)}+\frac{\pi D \sigma \sqrt{L(Q)}}{Q(1-y)} \frac{\partial}{\partial k}(\psi(k)) \\
& =h_{b 2} \sigma \sqrt{L(Q)}-\frac{\pi D \sigma \sqrt{L(Q)}}{Q(1-y)} \bar{F}(k)
\end{aligned}
$$


Operations Research and Applications : An International Journal (ORAJ), Vol.3, No.1, February 2016

$$
\begin{array}{rlrl}
\frac{\partial^{2}}{\partial k^{2}} E T C & =-\frac{\pi D \sigma \sqrt{L(Q)}}{Q(1-y)}\left(1-\frac{1}{\sqrt{2 \pi}} \int_{0}^{k} e^{-\frac{z^{2}}{2}} d z\right) \\
& =\frac{\pi D \sigma \sqrt{L(Q)}}{Q(1-y)} \phi(z)>0 & \forall k \geq 0
\end{array}
$$

Put

$$
\frac{\partial}{\partial k} E T C=0
$$

We get

$$
\bar{F}(k)=h_{b 2} \frac{Q(1-y)}{\pi D}
$$

Next, equating zero the first derivative of ETC with respect to Q.

$$
\begin{gathered}
\frac{\partial}{\partial Q} E T C=\frac{-G(n) D}{(1-y) Q^{2}}+h_{b 1}\left(y-\frac{D y}{2 x(1-y)}\right)+\frac{h_{v}}{2}\left[n\left(1-\frac{D p}{1-y}\right)-1+\frac{2 D p}{1-y}\right]+h_{b 2}\left(\frac{k \sigma p}{2 \sqrt{p Q+b}}+\frac{1-y}{2}+\frac{D y}{2 x(1-y)}\right) \\
+\frac{\pi D \sigma \psi(k)}{1-y}\left[\frac{\frac{p Q}{2 \sqrt{p Q+b}}-\sqrt{p Q+b}}{Q^{2}}\right]=0 \\
\frac{-G(n) D}{Q^{2}}+H(n)+h_{b 2} \frac{k \sigma p}{2 \sqrt{L(Q)}}(1-y)+\frac{\pi D \sigma \psi(k)(p Q-2 L(Q))}{2 Q^{2} \sqrt{L(Q)}}=0
\end{gathered}
$$

where,

$$
\begin{gathered}
H(n, y)=h_{b 1}\left(y(1-y)-\frac{D y}{2 x}\right)+\frac{h_{v}}{2}(-(n-2) D p+(n-1)(1-y))+h_{b 2}\left(\frac{(1-y)^{2}}{2}+\frac{D y}{2 x}\right) \\
G(n)=(A+B+n F) / n \\
H(n, y)+\frac{h_{b 2} \sigma p(1-y)}{2 \sqrt{L(Q)}\left(k+\frac{\psi(k)}{\bar{F}(k)}\right)=\frac{D}{Q^{2}}(\pi \sigma \psi(k) \sqrt{L(Q)}+G(n))} \\
Q=\sqrt{\frac{D \pi \sigma \psi(k) \sqrt{L(Q)}+D G(n)}{H(n, y)+\frac{h_{b 2} p \sigma(1-y)}{2 \sqrt{L(Q)}}\left(k+\frac{\psi(k)}{\bar{F}(k)}\right)}}
\end{gathered}
$$


Operations Research and Applications : An International Journal (ORAJ), Vol.3, No.1, February 2016

\section{ALGORITHM}

Step 1. Set $E T C^{*}=\infty$ and $n=1$.

Step 2. Compute $Q=\left[\sqrt{\frac{D G(n)}{H(n)}}\right]$ where $[x]$ the nearest integer of $x$.

Step 3. Find $k$ from (8) and Compute $\psi(k)$ using (3)

Step 4. Compute $Q^{\prime}$ using (9) and, Set $Q^{\prime}$ by $\left[Q^{\prime}\right]$

Step 5. If $\left|Q^{\prime}-Q\right|=0$, compute $\operatorname{ETC}(Q, n)$ and go to Step 6. If $\left|Q^{\prime}-Q\right|>0$, set $Q$ by $Q^{\prime}$ and go to step 3 .

Step 6. If $\operatorname{ETC}^{*} \geq \operatorname{ETC}(Q, n)$, then set $\operatorname{ETC}^{*}$ by $\operatorname{ETC}(Q, n), Q^{*}$ by $Q$, $r^{*}$ by $r$, and $n$ by $n+1$ and go to step 2 . Otherwise set $n *$ by $n-1$ and stop.

\section{NUMERICAL EXAMPLE}

For numerical studies, we consider the following data set:

$D=1000 ; \quad P=3200 ; \quad A=50 ; \quad F=35 ; \quad h_{v}=4 ; \quad h_{b 1}=6 ; \quad h_{b 2}=10 ; s=0.25 ; x=2152 ; w=20 ; y$ $=0.33$; $\pi=100 ; b=0.01$.

From table 1 we have the optimum number of shipments $n^{*}=7$.

The optimum order quantity $Q^{*}=106$.

The optimum reorder level $r^{*}=45$. 
Operations Research and Applications : An International Journal (ORAJ), Vol.3, No.1, February 2016 The following table shows that optimal number of shipments and optimal batch quantity.

\begin{tabular}{|c|c|c|c|}
\hline$n$ & $Q$ & $r$ & $E T C$ \\
\hline 1 & 327 & 115 & 14,073 \\
2 & 223 & 83 & 13,298 \\
3 & 176 & 68 & 13,024 \\
4 & 149 & 59 & 12,881 \\
5 & 130 & 53 & 12,815 \\
6 & 116 & 49 & 12,784 \\
7 & $\mathbf{1 0 6}$ & $\mathbf{4 5}$ & $\mathbf{1 2 , 7 7 6}$ \\
8 & 98 & 43 & 12,782 \\
9 & 91 & 40 & 12,794 \\
\hline
\end{tabular}

Table: 1

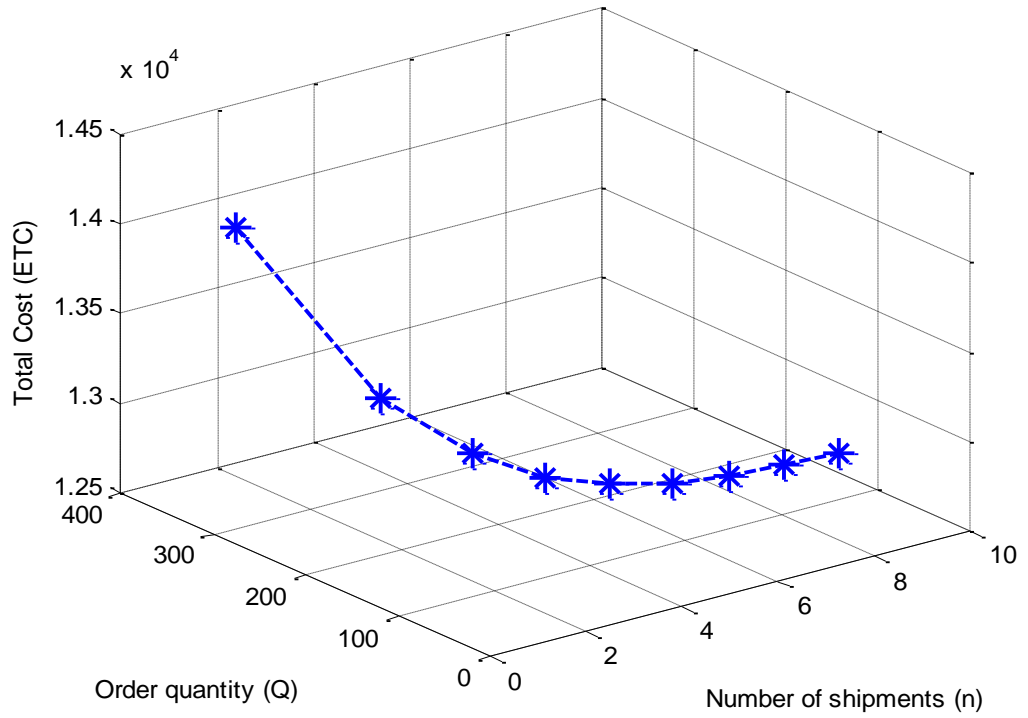

Fig 2 Graphical representation of optimal solutions for ETC with respect to Q and $\mathrm{n}$. 
Operations Research and Applications : An International Journal (ORAJ), Vol.3, No.1, February 2016

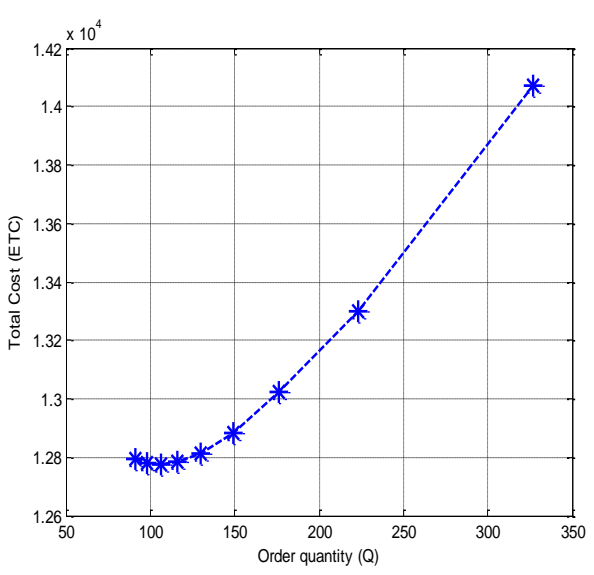

Fig 3

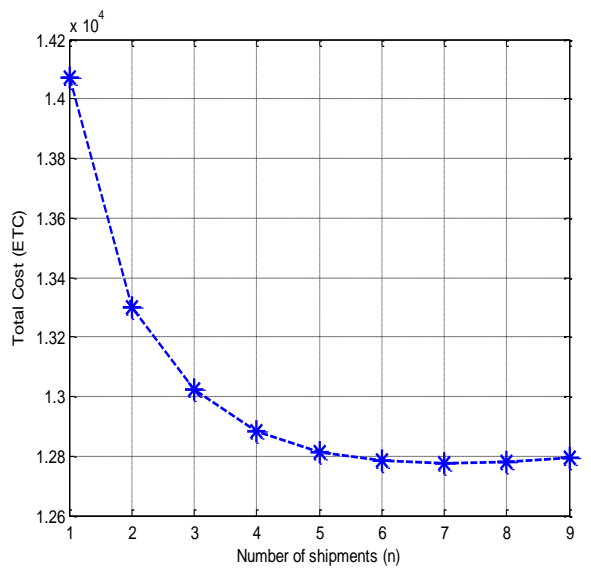

Fig 4

Graphical representation ETC with respect to Q Graphical representation ETC with respect to n.

\section{SENSITIVE ANALYSIS}

The sensitive analysis of demand $D$ for $D+50 \%, D+25 \%, D-50 \%, D+25 \%$ is performed Tables 2-5 in order to various demand affect the optimal solutions of the proposed model. Also the effect of demands depicted in Fig 5-8.

\section{Effect of $D$ when it is $50 \%$ extra}

\begin{tabular}{|c|c|c|c|c|c|}
\hline Demand & $n$ & $Q$ & $r$ & $E T C$ & $k$ \\
\hline & 1 & 382 & 198 & 20,281 & 2.13 \\
& 2 & 269 & 145 & 19,147 & 2.26 \\
& 3 & 219 & 121 & 18,702 & 2.34 \\
1,500 & 4 & 189 & 107 & 18,471 & 2.39 \\
(i.e., & 5 & 168 & 97 & 18,334 & 2.43 \\
$D+50 \%)$ & 7 & 153 & 90 & 18,250 & 2.48 \\
& 8 & 132 & 84 & 18,201 & 2.5 \\
& 9 & 124 & 76 & 18,153 & 2.54 \\
& $\mathbf{1 0}$ & $\mathbf{1 1 8}$ & $\mathbf{7 3}$ & $\mathbf{1 8 , 1 4 8}$ & $\mathbf{2 . 5 6}$ \\
& 11 & 112 & 70 & 18,148 & 2.57 \\
& 12 & 107 & 68 & 18,153 & 2.6 \\
& 13 & 103 & 66 & 18,165 & 2.61 \\
\hline
\end{tabular}

Table 2 
Operations Research and Applications : An International Journal (ORAJ), Vol.3, No.1, February 2016

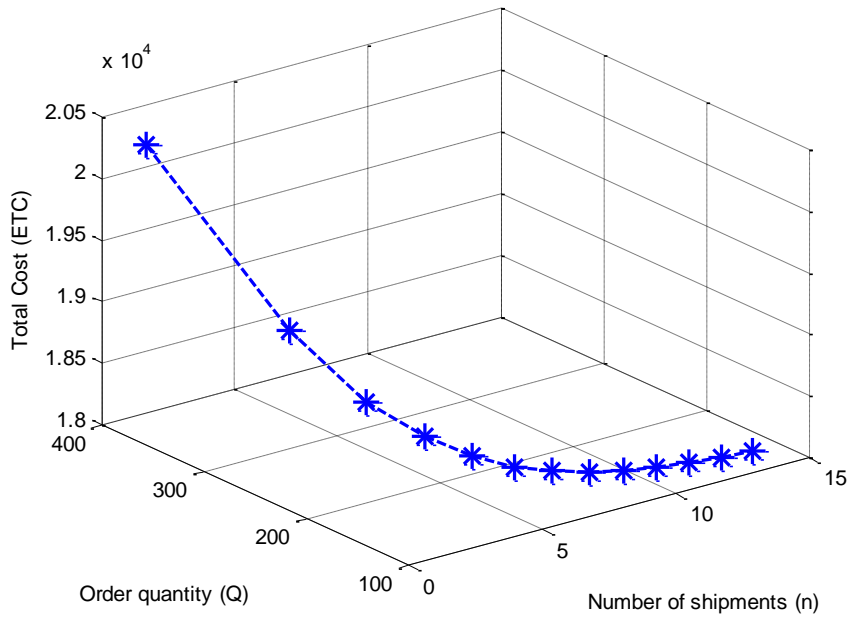

Fig 5 Graphical representation of optimal solutions for ETC with respect to Q and $n$ when $D=1500$

\section{Effect of $D$ when it is $25 \%$ extra}

\begin{tabular}{|c|c|c|c|c|c|}
\hline Demand & $n$ & $Q$ & $r$ & $E T C$ & $k$ \\
\hline \multirow{5}{*}{1,250} & 1 & 357 & 156 & 17,191 & 2.07 \\
& 2 & 247 & 112 & 16,235 & 2.22 \\
$($ i.e., & 3 & 198 & 93 & 15,874 & 2.3 \\
$D+25 \%)$ & 5 & 169 & 81 & 15,675 & 2.36 \\
& 6 & 149 & 74 & 15,597 & 2.41 \\
& 7 & 135 & 68 & 15,545 & 2.44 \\
& 8 & 115 & 64 & 15,518 & 2.48 \\
& $\mathbf{9}$ & $\mathbf{1 0 7}$ & 60 & 15,507 & 2.5 \\
& 10 & 101 & $\mathbf{5 7}$ & $\mathbf{1 5 , 5 0 6}$ & $\mathbf{2 . 5 3}$ \\
& 11 & 96 & 55 & 15,515 & 2.55 \\
& 11 & & 15,530 & 2.57 \\
\hline
\end{tabular}

Table 3 
Operations Research and Applications : An International Journal (ORAJ), Vol.3, No.1, February 2016

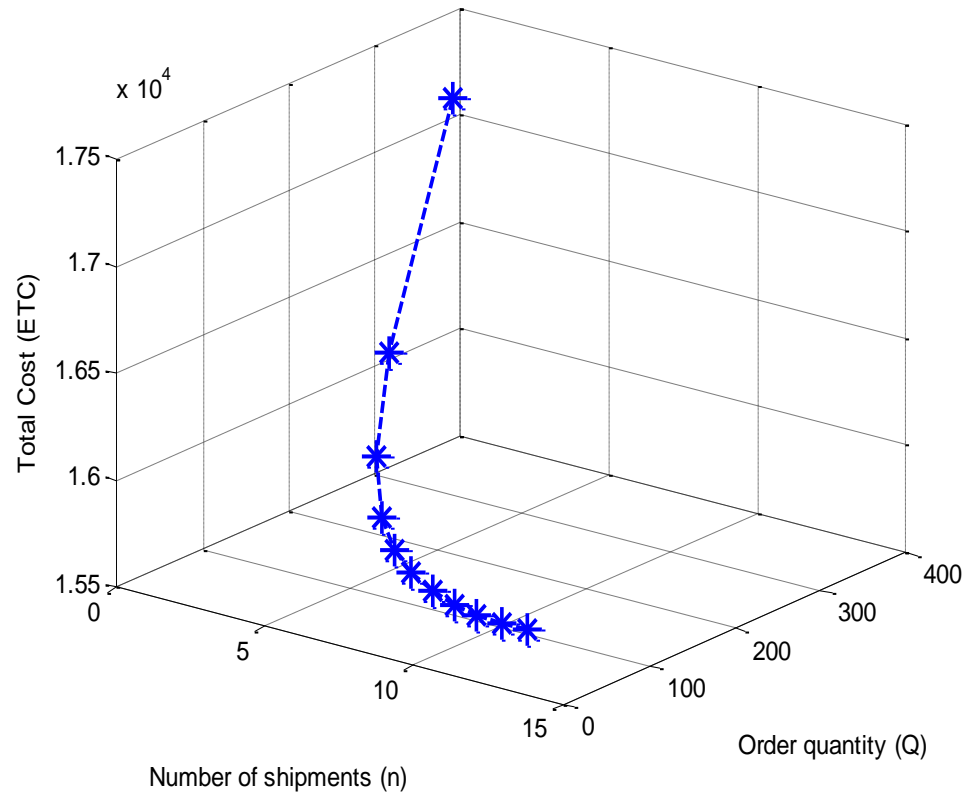

Fig 6 Graphical representation of optimal solutions for ETC with respect to Q and $n$ when $D=1250$

\section{Effect of $D$ when it is $25 \%$ less}

\begin{tabular}{|c|c|c|c|c|c|}
\hline Demand & $n$ & $Q$ & $r$ & ETC & $k$ \\
\hline & 1 & 291 & 79 & 10,917 & 1.94 \\
& 2 & 194 & 56 & 10,309 & 2.11 \\
(i.e., D-25\%) & 3 & 152 & 46 & 10,101 & 2.21 \\
& 4 & 126 & 40 & 10,009 & 2.28 \\
& 5 & 110 & 36 & 9,972 & 2.33 \\
& $\mathbf{6}$ & $\mathbf{9 8}$ & $\mathbf{3 3}$ & $\mathbf{9 , 9 6 2}$ & $\mathbf{2 . 3 8}$ \\
& 7 & 88 & 31 & 9,967 & 2.42 \\
& 8 & 81 & 29 & 9,981 & 2.44 \\
\hline
\end{tabular}

Table 4 
Operations Research and Applications : An International Journal (ORAJ), Vol.3, No.1, February 2016

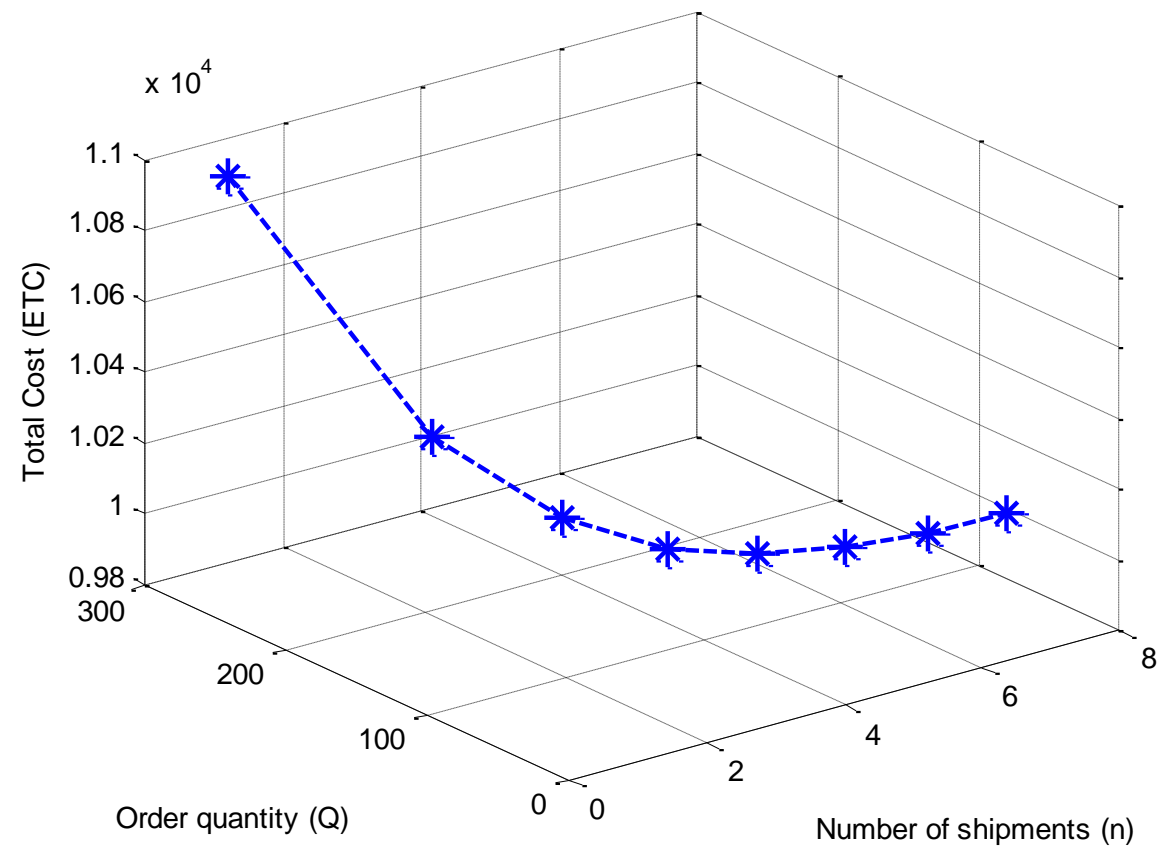

Fig 7 Graphical representation of optimal solutions for ETC with respect to Q and $\mathrm{n}$ when $\mathrm{D}=750$

\section{Effect of $D$ when it is $50 \%$ less}

\begin{tabular}{|c|c|c|c|c|c|}
\hline Demand & $n$ & $Q$ & $r$ & $E T C$ & $k$ \\
\hline & 1 & 245 & 46 & 7,696 & 1.84 \\
& 2 & 160 & 32 & 7,255 & 2.03 \\
500 & 3 & 123 & 27 & 7,113 & 2.13 \\
& 4 & 102 & 23 & 7,059 & 2.21 \\
& $\mathbf{5}$ & $\mathbf{8 7}$ & $\mathbf{2 1}$ & $\mathbf{7 , 0 4 1}$ & $\mathbf{2 . 2 7}$ \\
& 6 & 77 & 19 & 7,043 & 2.31 \\
& 7 & 70 & 18 & 7,059 & 2.35 \\
\hline
\end{tabular}

Table 5 


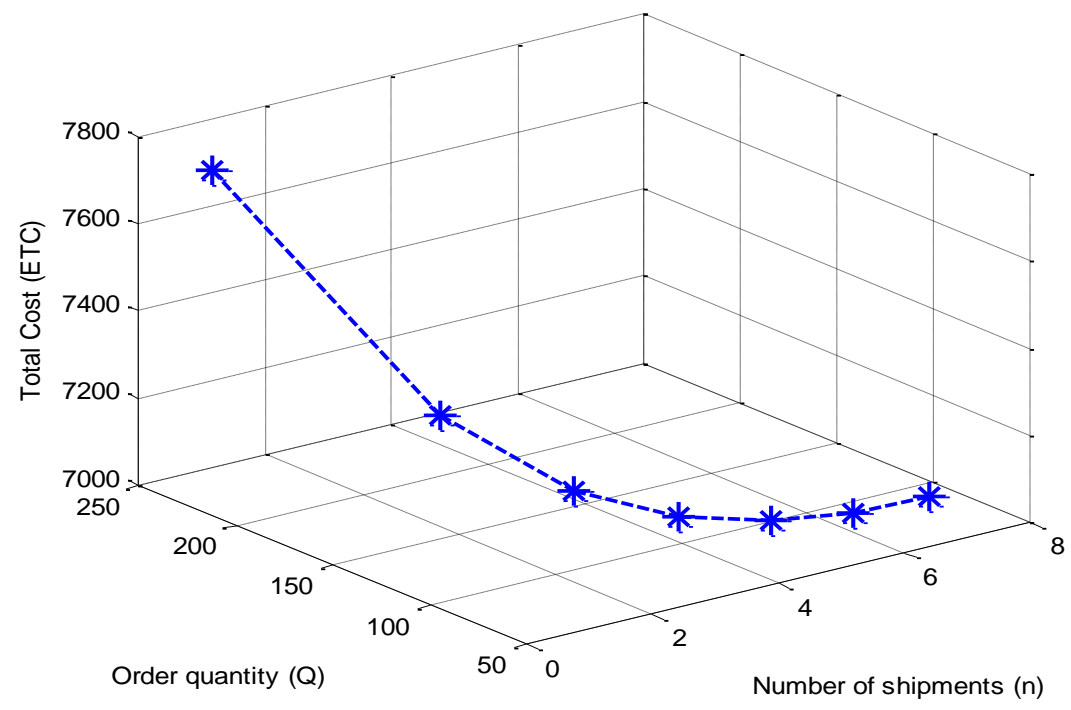

Fig 8 Graphical representation of optimal solutions for ETC with respect to Q and $\mathrm{n}$ when $\mathrm{D}=500$

\section{CONCLUSION}

In this paper, we considered the single vendor single buyer integrated production inventory problem. Here, we assume that demand is stochastic; the lead time is variable and depends on batch size and other delays, such as transportation time. A simple procedure is suggested to obtain an approximate solution of the proposed model. Examples are used to illustrate the proposed model.

\section{ACKNOWLEDGEMENTS}

The authors would like to acknowledge the Editor of the Journal and anonymous reviewer for their encouragement and constructive comments in revising the manuscript. The $2^{\text {nd }}$ author is grateful to the Department of Science and Technology - Science and Engineering Research Board (DST-SERB), Government of India, New Delhi, for providing financial assistance in the form Fellowship under the scheme of DST-SERB Research Project with DST-SERB/SR/S4/MS: 814/13-Dated 24.04.2014.

\section{REFERENCE}

[1] Banerjee, A., 1986. "A joint economic-lot-size model for purchaser and vendor. Decision Sciences" 17, 292-311.

[2] Ben-Daya, M., Hariga, M., 2004. "Integrated single vendor single buyer model with stochastic demand and variable lead-time." International Journal of Production Economics .92, 75-80.

[3] Ben-Daya, M., Hariga, M., 2000. "Economic lot scheduling problem with imperfect production processes." Journal of the Operational Research Society 51, 875-881.

[4] Dey.O, Giri. B.C 2014. "Optimal vendor investment for reducing defect rate in a vendor-buyer integrated system with imperfect production process". International Journal of Production Economics. 
Operations Research and Applications : An International Journal (ORAJ), Vol.3, No.1, February 2016

[5] Goyal, S.K., 1988. "A joint economic-lot-size model for purchaser and vendor: A comment." Decision Sciences 19, 236-241.

[6] Goyal, S.K., Gupta, Y.P., 1989. "Integrated inventory models: The buyer-vendor coordination." European Journal of Operational Research 41, 261-269.

[7] Hoque, M.A., Goyal, S.K., 2000. "An optimal policy for a single-vendor single-buyer integrated production-inventory system with capacity constraint of the transport equipment." International Journal of Production Economics 65, 305-315.

[8] Huang, C.K., 2004. "An optimal policy for a single-vendor single-buyer integrated productioninventory problem with process unreliability consideration." International Journal of Production Economics. 91, 91-98

[9] Karmarkar, U.S., 1987. "Lot sizes, lead times and in-process inventories." Management Science 33, 409-418.

[10] Kim, J.S., Benton, W.C., 1995. "Lot size dependent lead times in a (Q,r) inventory system." International Journal of Production Research 33, 41-58.

[11] Lee, H.L., Rosenblatt, M.J., 1987. "Simultaneous determination of production cycles and inspection schedules in a production system." Management Science 33, 1125-1137.

[12] Porteus, E.L., 1986. "Optimal lot sizing, process quality improvement and setup cost reduction." Operations Research 34 (1), 137-144.

[13] Vandana, B.K.Sharma., 2016. "An EOQ model for retailers partial permissible delay in payment linked to order quantity with shortages." Mathematical Computational Simulation.

[14] Vandana, B.K.Sharma., 2015. "An EPQ inventory model for non-instantaneous deteriorating items under trade credit policy." International Journal of Mathematical Science and Engineering Applications. 9(1), 179-188.

[15] Vandana, B.K.Sharma., 2015. "An inventory model for Non-instantaneous deteriorating items with quadratic demand rate and shortages under trade credit policy." Journal of Applied Analysis and Computation. In press.

[16] V.N.Mishra, Some Problems on Approximations of Functions in Banach Spaces, Ph.D. Thesis (2007), Indian Institute of Technology, Roorkee, UP, India. 